\title{
Importance of $\beta_{2}$-adrenoceptor stimulation in the suppression of intradermal antigen challenge by adrenaline
}

\author{
J. B. WARREN, F. J. PIXLEY \& C. T. DOLLERY \\ Department of Clinical Pharmacology, Hammersmith Hospital, London W12 0NN
}

1 Seven atopic subjects received two injections of antigen and one of saline intradermally in the back on each of 4 separate days. They were pretreated with four different drug combinations: (a) adrenaline $0.3 \mathrm{mg}$ subcutaneously over the deltoid muscle (b) subcutaneous adrenaline preceded by $5 \mathrm{mg}$ of the specific $\beta_{2}$-adrenoceptor antagonist ICI 118,551 orally (c) $8 \mathrm{mg}$ of salbutamol orally (d) placebo. Tablets were given $2 \mathrm{~h}$ before and subcutaneous injections $15 \mathrm{~min}$ before the intradermal injections of saline and antigen.

2 The median flare response to intradermal low dose antigen and high dose antigen after pretreatment with adrenaline was $4 \%$ and $49 \%$ of the response seen following pretreatment with placebo $(P<0.001)$. When adrenaline was preceded by ICI-118,551, the corresponding median flare responses were $2 \%$ and $44 \%(P<0.001)$ of the placebo response. The flare response after pretreatment with salbutamol was not significantly different from placebo.

3 Adrenaline suppressed the median weal response to the higher dose of antigen to $52 \%$ of the response after pretreatment with placebo $(P<0.05)$. This suppression by adrenaline was blocked by pretreatment with ICI 118,551. The median weal response after the highest dose of antigen was suppressed by salbutamol to $66 \%$ of the response seen after placebo, although this was not significant even when a further three subjects were studied with either salbutamol or placebo.

4 These results confirm that a small dose of systemic adrenaline attenuates the weal and flare response to intradermal antigen. This suppression of the weal response is blocked by a $\beta_{2}$-adrenoceptor antagonist although it is only partially mimicked by high dose oral salbutamol. The suppression of the flare response may involve $\alpha$-adrenoceptor stimulation.

Keywords adrenaline $\beta_{2}$-adrenoceptor antagonists antigen salbutamol

\section{Introduction}

It has previously veen shown that the skin response to antigen may be suppressed if $0.3 \mathrm{mg}$ of adrenaline is injected systemically before the challenge (Warren et al., 1988). This is an important observation because the ability to suppress both the weal and fiare of the immediate hypersensitivity reaction to antigen, with even a relatively small dose of adrenaline, underlies the rationale for using this drug in acute anaphylaxis.

The major clinical indication for $\boldsymbol{\beta}_{2}$ adrenoceptor agonists is for the treatment of asthma where they are thought to bronchodilate by relaxing airway smooth muscle. However, it

Correspondence: Dr J. B. Warren, Clinical Pharmacology, RPMS Hammersmith Hospital, Du Cane Road, London W12 0NN 
has been suggested that much of the airway narrowing of asthma is attributable to inflammatory oedema (Hogg et al., 1987). The attenuation by adrenaline of both oedema formation and the associated flare of injected antigen is of additional theoretical benefit in the treatment of asthma as well as to the known $\beta_{2}$ receptor mediated relaxation of smooth muscle.

The importance of $\beta_{2}$-adrenoceptor stimulation in the suppression of intradermal antigen response has been investigated in the present study by comparing the efficacy of systemic adrenaline to oral salbutamol and by giving a specific $\beta_{2}$-adrenoceptor antagonist, ICI 118,551 before the administration of adrenaline.

\section{Methods}

Seven atopic healthy men, aged $21-30$ years, who gave informed consent were studied. The protocol was approved by the hospital Ethics Committee. For the pre-study assessment, increasing doses of house dust mite or grass pollen antigen (Pharmacia, Sweden) were given as $50 \mu$ intradermal injections with a 27 gauge needle into the skin of the back. The antigen solutions were diluted with $0.9 \%$ saline to give concentrations of $0.5,1,5,10,50$ and 100 units $\mathrm{ml}^{-1}$. Increasing doses of antigen were given until a flare reaction of at least a $2 \mathrm{~cm}$ diameter was obtained. This dose of antigen, together with a dose one tenth the concentration, and a saline control, were used to produce a dose response. Any subject with a history of asthma was excluded.

All subjects were pretreated with a tablet by mouth followed by a subcutaneous injection at $1 \mathrm{~h} 45 \mathrm{~min}$ and intradermal injections of antigen at $2 \mathrm{~h}$. The four treatment days were:-

$\begin{array}{ll}\begin{array}{l}\text { Oral } \\ \text { Placebo }\end{array} & \begin{array}{l}\text { Injection } \\ \text { Placebo }\end{array} \\ \text { ICI 118,551 25 mg } & \begin{array}{l}\text { Adrenaline 0.3 mg } \\ \text { Adrenaline 0.3 mg }\end{array} \\ \text { Placebo } & \text { Placebo } \\ \text { Salbutamol } 8 \mathrm{mg} & \text { Place }\end{array}$

and these were given in randomized order on four separate occasions 1 week apart. The flare was measured $15 \mathrm{~min}$ after the intradermal injections by tracing the area onto a perspex sheet. At 20 min after the intradermal injections, the weal was traced with ink and this was removed by adhesive tape. The areas of weal and flare were later determined by planimetry. The traces were drawn by an independent observer who was blind to the protocol. It was originally intended to study 10 subjects but ICI-118,551 was withdrawn from clinical trials by the manufacturer after only seven subjects had completed the protocol. Therefore, a further three atopic healthy men were recruited (aged 28-33 years) and they were studied according to the above protocol except that they only completed the placebo and salbutamol day.

Significance was tested by 2 -tailed Wilcoxon matched pairs signed rank sum test.

\section{Results}

The subjects experienced no side effect from the study apart from an increase in physiological tremor induced by adrenaline and salbutamol and some itch over the skin test site. Table 1 shows the dose and type of antigen used. Table 2 and Figure 1 show the effect of pretreatment with placebo, systemic adrenaline, systemic adrenaline with ICI-118,551 or salbutamol on the weal and flare response. The low dose of antigen had little effect on weal size but caused a 34 fold increase in flare response compared with the flare after intradermal saline. The flare response was significantly suppressed by adrenaline in the presence or absence of ICI$118,551(P<0.001$ in each case). Of the weal responses, only the higher dose of antigen was suppressed by adrenaline $(P<0.05)$. Table 3 shows the data for the ten subjects who took salbutamol or placebo and includes data on three individuals who are not included in Table 2.

\section{Discussion}

The present study confirms our previous finding that a small dose of adrenaline given systemically is capable of protecting against both the weal and flare caused by intradermal antigen (Warren et al., 1988). Adrenaline caused a marked suppression of the flare response and this was unaffected by pretreatment by the specific $\beta_{2}$-adrenoceptor antagonist, ICI118,551 .

Table 1 Type and dose of antigen used in the 10 subjects.

\begin{tabular}{lcc}
\hline Subject & \multicolumn{2}{c}{ Type and dose of antigen ${\text { (units } \mathrm{ml}^{-1} \text { ) }}^{-1,10}$} \\
$1-4$ & GP & $1,10,100$ \\
5 & GP & 10,100 \\
$6-9$ & HD & $0.5,5$ \\
10 & HD & \\
\hline
\end{tabular}

$\mathrm{HD}=$ house dust mite; GP = grass pollen 
Table 2 Effect of pretreatment with placebo, adrenaline $0.3 \mathrm{mg}$ systemically, adrenaline $0.3 \mathrm{mg}$ systemically with $5 \mathrm{mg}$ ICI-118,551 orally or salbutamol $8 \mathrm{mg}$ orally on the weal and flare response of the seven subjects. Data are median ( $95 \%$ confidence intervals)

\begin{tabular}{|c|c|c|c|c|c|}
\hline & & Placebo & Adrenaline & $\begin{array}{l}\text { Adrenaline }+ \\
\text { ICI-118,551 }\end{array}$ & Salbutamol \\
\hline \multirow{3}{*}{ Weal } & Saline & $\begin{array}{c}0.83 \\
(0.47-0.95)\end{array}$ & $\begin{array}{c}0.99 \\
(0.76-1.10)\end{array}$ & $\begin{array}{c}0.81 \\
(0.73-0.89)\end{array}$ & $\begin{array}{c}0.86 \\
(0.71-1.01)\end{array}$ \\
\hline & $\mathrm{Ag}$ & $\begin{array}{c}1.02 \\
(0.68-1.55)\end{array}$ & $\begin{array}{c}1.02 \\
(0.75-1.10)\end{array}$ & $\begin{array}{c}0.98 \\
(0.82-1.24)\end{array}$ & $\begin{array}{c}1.02 \\
(0.89-1.12)\end{array}$ \\
\hline & $10 x \mathrm{Ag}$ & $\begin{array}{c}2.28 \\
(1.20-3.26)\end{array}$ & $\begin{array}{c}1.19^{*} \\
(0.98-1.92)\end{array}$ & $\begin{array}{c}1.67 \\
(1.24-2.72)\end{array}$ & $\begin{array}{c}1.51 \\
(0.99-2.33)\end{array}$ \\
\hline \multirow{3}{*}{ Flare } & Saline & $\begin{array}{c}0.35 \\
(0-1.71)\end{array}$ & $\begin{array}{c}0^{*} \\
(0-0.17)\end{array}$ & $\begin{array}{c}0^{*} \\
(0-0.09)\end{array}$ & $\begin{array}{c}0.61 \\
(0.03-1.51)\end{array}$ \\
\hline & $\mathrm{Ag}$ & $\begin{array}{c}11.92 \\
(4.79-14.97)\end{array}$ & $\begin{array}{l}0.49^{*} \\
(0-2.09)\end{array}$ & $\begin{array}{l}0.29 * \\
(0-3.45)\end{array}$ & $\begin{array}{c}5.35 \\
(0.53-11.62)\end{array}$ \\
\hline & 10x Ag & $\begin{array}{c}19.98 \\
(11.77-31.35)\end{array}$ & $\begin{array}{c}9.77^{*} \\
(4.57-20.27)\end{array}$ & $\begin{array}{c}8.84^{*} \\
(3.20-22.25)\end{array}$ & $\begin{array}{c}17.72 \\
(7.15-30.49)\end{array}$ \\
\hline
\end{tabular}

$*=P<0.05$ compared with placebo.
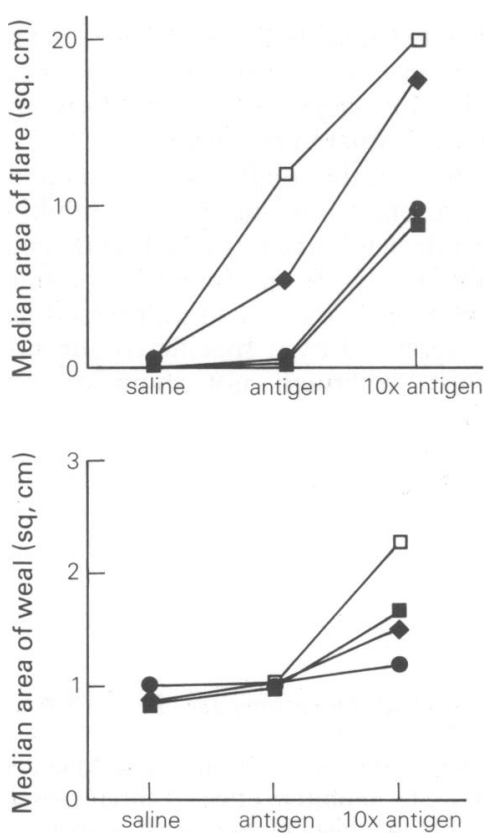

Figure 1 Median areas of weal and flare for the seven subjects in response to intradermal saline, antigen and tenfold dose of antigen. ( $\square$ ) placebo, $(\bullet)$ adrenaline $0.3 \mathrm{mg}$ systemically, ( $\square)$ adrenaline $0.3 \mathrm{mg}$ systemically with $5 \mathrm{mg}$ ICI-118,551 orally, ( salbutamol $8 \mathrm{mg}$ orally.

The flare response to intradermal antigen is thought to be mediated by an axon reflex but the exact mechanism is unknown (Chapman, 1977; Barnes et al., 1986). Vasodilation in the skin is inhibited by noradrenaline released locally by sympathetic nerves and therefore the injected
Table 3 Effect of pretreatment with placebo or salbutamol $8 \mathrm{mg}$ orally on the weal and flare response of the ten subjects. Dota are median ( $95 \%$ confidence intervals)

\begin{tabular}{llcc}
\hline & & Placebo & Salbutamol \\
\hline \multirow{4}{*}{ Weal } & Saline & 0.79 & 0.85 \\
& & $(0.60-0.82)$ & $(0.77-0.93)$ \\
& & 0.92 & 0.99 \\
& & $(0.72-1.22)$ & $(0.87-1.03)$ \\
& & 1.33 & 1.28 \\
& & $(1.19-2.43)$ & $(1.07-1.83)$ \\
Flare & Saline & 0.25 & 0.80 \\
& & $(1.12-1.22)$ & $(0.43-1.69)$ \\
& & 6.67 & 4.05 \\
& & $(4.15-10.69)$ & $(2.11-7.97)$ \\
& & 13.81 & 15.28 \\
& & $(12.50-23.88)$ & $(11.09-22.97)$ \\
\hline
\end{tabular}

Differences between the groups were not significant.

adrenaline could mimic this action by stimulation of vasoconstrictor $\alpha_{1}$-adrenoceptors. However, intravenous phenylephrine in a dose which has significant cardiovascular effects, does not suppress the flare response (Kram et $a l ., 1975)$ and this does not fit the hypothesis that adrenaline inhibits flare by $\alpha$-adrenoceptor stimulation. In contrast, clonidine, an $\alpha_{2^{-}}$ adrenoceptor agonist that decreases central sympathetic outflow, does inhibit both the weal and flare response to antigen in patients with asthma (Lindgren et al., 1987). It was argued that $\alpha_{2}$-adrenoceptor stimulation of sensory $C$ fibres in the skin explained this observation (Lindgren et al., 1987) and therefore adrenaline may inhibit flare by $\alpha_{2}$-adrenoceptor rather than $\alpha_{1}$-adrenoceptor stimulation. 
The inhibition of weal formation by adrenaline with the higher dose of antigen was blocked by pretreatment with ICI-118,551 suggesting that this is mediated via $\beta_{2}$-adrenoceptors. Antigen induced weal formation in the skin is a consequence of mediator release from mast cells activated by $\operatorname{IgE}$. Salbutamol is a potent inhibitor (some $10^{2}-10^{3}$ more potent than cromoglycate) of IgE mediated mediator release from the lung in vivo (Howarth et al., 1985) and in vitro (Church \& Young, 1983; Butchers et al., 1979). In the present study salbutamol showed a similar trend to adrenaline in reducing the weal response, although this did not reach significance.

It may be that a higher dose of salbutamol is needed since previous studies with oral $\beta$ adrenoceptor agonists have shown no suppression of skin test responses (Galant et al., 1973; Spector, 1978; Abramowitz et al., 1980), although the topical application or local injection of these drugs attenuates the response to intradermal antigen presumably by higher local concentrations (Mosko \& Marshall, 1954; Ting et al., 1983; Gronneberg et al., 1980). However, the dose of salbutamol used in the present study caused greater systemic side effects than adrenaline and the difference in efficacy between adrenaline and salbutamol in suppressing weal remains unexplained.

The systemic absorption of this dose of adrenaline has been previously studied and the dose used causes a peak venous plasma concentration $15 \mathrm{~min}$ after injection of approximately $2 \mathrm{nmol}$ $1^{-1}$, which remains raised for at least $40 \mathrm{~min}$ (Warren et al., 1986). The only previous work to

\section{References}

Abramowitz, W., Perez, M. M., Johnson, C. E. \& McLean, J. A. (1980). Effect of theophylline, terbutaline and their combination on immediate skin tests. J. Allergy clin. Immunol., 65, 61-64.

Barnes, P. J. Brown, M. J. Dollery, C. T. Fuller, R. W., Heavey, D. J. \& Ind, P. W. (1986). Histamine is released from skin by substance $P$ but does not act as the final vasodilator in the axon reflex. Br. J. Pharmac., 88, 741-745.

Butchers, P. R., Fullerton, Jr., Skidmore, I. F., Thompson, L. E., Vardey, C. J. \& Wheeldon, A. (1979). A comparison of the anti-anaphylactic activities of salbutamol and disodium cromoglycate in the rat, the rat mast cell and in human lung tissue. Br. J. Pharmac., 67, 23-32.

Chapman, L. F. (1977). Mechanisms of the flare reaction in human skin. J. invest. Dermatol., 69, 88-91.

Church, M. K. \& Young, K. D. (1983). The characteristics of inhibition of mediator release from human lung fragments by sodium cromoglycate, sal- study the effect of systemic adrenaline on the response to intradermal antigen used much higher doses of intravenous adrenaline, but found a similar suppressive effect (Kram et al., 1975).

A $0.3 \mathrm{mg}$ dose of adrenaline was chosen because this is still widely used in North America for the treatment of acute asthma and we had previously determined its pharmacokinetics (Warren et al., 1986). A dose of salbutamol of 8 mg gives some normal subjects an uncomfortable tremor, but we were reluctant to use a smaller dose because $8 \mathrm{mg}$ of the slow release preparation of salbutamol by mouth does not influence the skin weal and flare response to antigen (P.W. Ind, personal communication). ICI 118,551 has been shown to antagonize the $\beta_{2}$ effects of infused isoprenaline but not the $\beta_{1}$ effects in an optimum dose range of $25-50 \mathrm{mg}$ (J. D. Harry, data on file, ICI Pharmaceuticals Division, Macclesfield).

It was our original intention to study 10 subjects but because ICI-118,551 has been withdrawn from clinical trials it was necessary to curtail the investigation after only seven volunteers had completed the protocol.

In summary, the small dose of adrenaline used in the present study significantly inhibited the flare response to intradermal antigen in man and this may be by $\alpha_{2}$-adrenoceptor stimulation. The weal response was also suppressed, and this was antagonized by a specific $\beta_{2}$-adrenoceptor antagonist, although not mimicked by salbutamol.

We thank Dr J. D. Harry for his help.

butamol and chlorpromazine. Br. J. Pharmac., 78, 671-679.

Galant, S. P., Bullock, J., Wong, D. \& Maibach, I. H. (1973). The inhibitory effect of antiallergy drugs on allergen and histamine-induced wheal and flare response. J. Allergy clin. Immunol., 51, 11-21.

Gronneberg, R., Strandberg, K. \& Hagermark, O. (1980). Cutaneous response to allergen after local pretreatment with beta-adrenoceptor stimulating and blocking agents. Allergy, 35, 409-412.

Hogg, J. C., Pare, P. D. \& Moreno, R. (1987). The effect of submucosal edema on airway resistance. Ann. Rev. resp. Dis., 135, s54-56.

Howarth, P. H., Durham, S. R., Lee, T. H., Kay, A. B., Church, M. K. \& Holgate, S. T. (1985). Influence of albuterol, cromolyn sodium and ipratropium bromide on the airway response to allergen bronchial provocation in asthma. Ann. Rev. resp. Dis., 132, 986-992.

Kram, J. A., Boune, H. R., Maiback, H. I. \& 
Melmon, K. L. (1975). Cutaneous immediate hypersensitivity in man: effects of systemically administered adrenergic drugs. J. Allergy clin. Immunol., 56, 387-392.

Lindgren, B. R., Brundin, A. \& Anderson, R. G. G. (1987). Inhibitory effects of clonidine on the allergen-induced wheal-and-flare reactions in patients with extrinsic asthma. J. Allergy clin. Immunol., 79, 941-946.

Mosko, M. M. \& Marshall, R. B. (1954). A study of the effect of various drugs on the whealing reaction. J. Allergy, 21, 242-251.

Spector, S. L. (1978). Effect of beta-adrenergic agents on skin test responses and bronchial challenge responses. Chest, 73, 976-977.
Ting, S., Zweiman, B. \& Lavker, R. (1983). Terbutaline modulation of human allergic skin reactions. J. Allergy clin. Immunol., 71, 437-441.

Warren, J. B., Doble, N., Dalton, N. \& Ewan, P. W. (1986). Systemic absorption of inhaled epinephrine. Clin. Pharmac. Ther., 40, 673-678.

Warren, J. B., McCusker, M. \& Fuller, R. W. (1988). Systemic adrenaline attenuates skin response to antigen and histamine. Clin Allergy, 18, 197-199.

(Received 16 June 1988, accepted 3 October 1988) 